\title{
Ge Graphos

\section{DEL NOSTÁLGICO RECUERDO AL CRECIENTE ENTUSIASMO POR LO RURAL. INDICIOS DE LA REVALORIZACIÓN Y EL RETORNO A LOS ESPACIOS RURALES}

\author{
Luciana Vanesa Clementi \\ Licenciatura en Geografía. Universidad Nacional del Centro de la Provincia de Buenos \\ Aires (Tandil, Argentina) \\ Correo electrónico: lucheana@hotmail.com
}

Recibido: 20 de junio de 2012. Devuelto para revisión: 15 de julio de 2012. Aceptado: 7 de agosto de 2012

\section{RESUMEN}

El presente artículo pretende analizar las transformaciones territoriales desde los vínculos urbano-rurales para comprender los procesos de revalorización de los Espacios Rurales (ER). En los últimos años, las demandas urbanas se hacen cada vez más presente; las mismas infieren nuevos usos productivos y no productivos que trastocan la evolución de los Asentamientos de Rango Menor (ARM) en diferentes aspectos, aunque en el universo analizado se destaca solo el re poblamiento. Sin embargo, la revalorización de lo rural tiene lugar de manera paralela a la sensación de crisis de sus habitantes. Por esta razón, si bien no se debe ignorar el evidente declive y los fenómenos de exclusión que algunas áreas rurales aún siguen generando, tampoco se puede dejar de reconocer los signos de reactivación y procesos emergentes positivos de otras. En este sentido, partiendo de la base que los espacios rurales son productos en sí mismos y no meros escenarios de hechos externos a ellos, este trabajo intentará, mediante un estudio de caso, plantear ciertos procesos y acciones sociales que enuncian signos de recuperación y de incipiente retorno a lo rural.

Palabras claves: Vínculos urbano-rurales, revalorización, retorno. 
FROM THE NOSTALGIC MEMORY TO THE INCREASING ENTHUSIASM FOR RURAL PLACES. SIGNS OF REVALUATION AND RETURN TO RURAL AREAS

\begin{abstract}
The hereby article will provide an analysis of territorial changes concerning rural-urban relationships in order to understand revaluation processes of Rural Areas (RA). During the last few years, urban demands have become more current. They imply new productive and nonproductive uses which change the Settlement of Lower Level (SLL) evolution in different aspects; although in the analyzed universe, only repopulation stands out. However, rural revaluation takes place in parallel to the crisis feeling of its inhabitants. Therefore, neither the obvious decline and the exclusion phenomenon, that some rural areas are still generating, nor the redevelopment signs and positive emerging processes from other areas should not been ignored. Hence, taking into account that rural areas are products and they are not just sceneries of external facts, this paper will attempt, by a case study, to explain certain processes and social actions which enunciate signs of recovery and incipient return to rural areas.
\end{abstract}

Key words: Rural-Urban Relationships, Revaluation, Return.

\title{
DA NOSTÁLGICA RECORDAÇÄO AO CRESCENTE ENTUSIASMO PELO RURAL. INDÍCIOS DA REVALORIZAÇÄO E O RETORNO AOS ESPAÇOS RURAIS
}

\section{RESUMO}

O presente artigo pretende analisar as transformaçöes territoriais desde os vínculos urbano rurais para compreender os processos de revalorizaçäo dos espaços rurais (ER). Nos últimos anos, as demandas urbanas se fazem cada vez mais presentes; as mesmas inferem novos usos produtivos e näo produtivos que transtrocam a evoluçäo dos assentamentos de hierarquia menor (AHM) em diferentes aspectos ainda que no universo analisado destaca-se só o repovoamento. Embora, a revalorizaçäo do rural tem lugar de maneira paralela à sensaçäo de crise de seus habitantes. Por essa razäo, bem que näo se deve ignorar a evidente declinaçäo e os fenömenos de exclusäo que algumas áreas rurais ainda continuam gerando, também näo se pode deixar de reconhecer os signos de reativaçäo e processos emergentes positivos de outras. Nesse sentido, partindo da base que os espaços rurais säo produtos em si mesmos e näo meros cenários de fatos externos a eles, este trabalho intentará, mediante um estudo de caso, plantear certos processos e açöes sociais que enunciam signos de recuperaçäo e de incipiente retorno ao rural.

Palavras-chave: Vínculos urbano-rurais, revalorizaçäo, retorno.

\section{INTRODUCCIÓN}

Los espacios rurales vienen experimentando profundos transformaciones fruto de la intensificación cambiante de los vínculos urbano-rurales insertos en relaciones 
multiescalares inestables, cuyos resultados se plasman en una realidad rural compleja. Al histórico proceso de concentración de la tierra y a la reciente capitalización y mecanización de las actividades agrícolas, se suma el crecimiento de actividades no agrícolas, es decir, el surgimiento de nuevos usos que la sociedad urbana le demanda a los espacios rurales y que dan lugar a acciones antes desconocidas como la revalorización de la vida rural.

El sistema de asentamientos, ha constituido objeto de trabajo de numerosos programas de investigación, nucleando dos grandes perspectivas de análisis; por un lado, ha dominado el estudio de transformaciones territoriales con privilegio de la aproximación económico-demográfica para comprender los cambios en el dinamismo local, en el rol funcional y en la jerarquía regional experimentados por cada uno de los asentamientos y/o por el sistema en su conjunto. Por otro lado, se han desarrollado numerosos trabajos donde los asentamientos se han analizado como objetos de conocimiento en sí mismos, aislados de toda trama de relaciones al interior de los sistemas territoriales en los cuales se inscriben.

Por su parte, este artículo plantea como objetivo general analizar las transformaciones territoriales rurales desde los vínculos urbano-rurales para comprender los procesos de revalorización de los ER. El trabajo empírico se realizó en ARM de la provincia de Buenos Aires, entendidos como población aglomerada por fuera de las cabeceras departamentales (Jacinto, 2012), los cuales son identificados como "Lugares donde se desenvuelve la base económica local con una específica dotación de recursos y dinámica de actores; son centros de servicio para las poblaciones residentes y los territorios circundantes, son territorios de proximidad y de sociabilidad más o menos intensa según los vínculos de proximidad, vecindad y parentesco; y lugares de memoria y patrimonio que conservan las trazas del pasado" (Pagès y Pélissier, 2000, p. 34). Estos territorios son heterogéneos, sus dinámicas expresan diferentes niveles de articulación funcional, institucional y espacial urbano-rural y son componente esencial de la matriz geográfica provincial.

Resulta oportuno recordar que la pérdida de población es un fenómeno que caracterizó por años a los espacios rurales en general y en particular a los ARM. Sin embargo, según los estudios realizados, este fenómeno parece transitar por un camino de inflexión y comenzar a ser ligeramente mitigado por un proceso de recuperación, por lo menos en los espacios rurales pampeanos argentinos y particularmente en los ARM analizados. De todas maneras, cabe aclarar, que si bien es un fenómeno que se está dando en el área de desarrollo del presente proyecto ${ }^{1}$, no es posible generalizarlo.

Vinculado a lo anterior, resulta propicio traer al análisis una cita que en cierta manera aporta claridad para comprender los "procesos contradictorios" que se manifiestan en el territorio. M. Manzanal afirma: "En los hechos, los ER son ámbitos de procesos contradictorios que tanto parecieran ir conduciendo hacia la pérdida de sus tradicionales particularidades (centradas en el trabajo agropecuario, en el asentamiento disperso) como revitalizando otras (a partir de la revalorización de la vida en el campo, el turismo rural, la conservación medioambiental y la ampliación del trabajo rural no agropecuario)" (2005, p. 13). Por otro lado, M. Murmis y S. Feldman coinciden cuando expresan: "Es una realidad el hecho de que en Argentina los pueblos crecen en un medio

\footnotetext{
1 "Construcción de indicadores para el análisis socioterritorial de los pueblos rurales bonaerenses" Beca de entrenamiento otorgada por la Comisión Científica de la provincia de Buenos Aires.
} 
rural que decrece" (2005, p. 23). Estas citas reflejan cambios y contradicciones que se resumen en una situación claramente paradójica, que obliga a reflexionar sobre los fenómenos y las dinámicas diferenciales que configuran el territorio.

Estos procesos contrapuestos se plasman en los espacios, originando escenarios rurales híbridos en constante mutación, donde áreas rurales antes marginales están siendo recientemente revalorizadas por nuevas demandas provenientes de nuevos ruralistas que pugnan por localizarse en los ARM.

¿Quiénes son los actores sociales que protagonizan estas transformaciones? ¿Por qué motivos? ¿Por qué en este momento histórico? Son algunas de las preguntas que no tienen una única respuesta pero que requieren ser respondidas, o por lo menos ameritan la realización de indagaciones para lo cual se torna el análisis de las articulaciones y los flujos de ida y vuelta entre los espacios rurales y los urbanos.

Por este motivo, este trabajo se centra en la indagación a través de indicadores que reflejen la realidad cambiante en general y la vuelta a lo rural en particular, a partir del estudio de caso realizado en los ARM de Cazón, Álvarez de Toledo, Del Carril y Polvaredas del partido de Saladillo, Provincia de Buenos Aires, Argentina. (Véase el mapa de la figura 1).

Figura 1. Situación relativa del Departamento de Saladillo

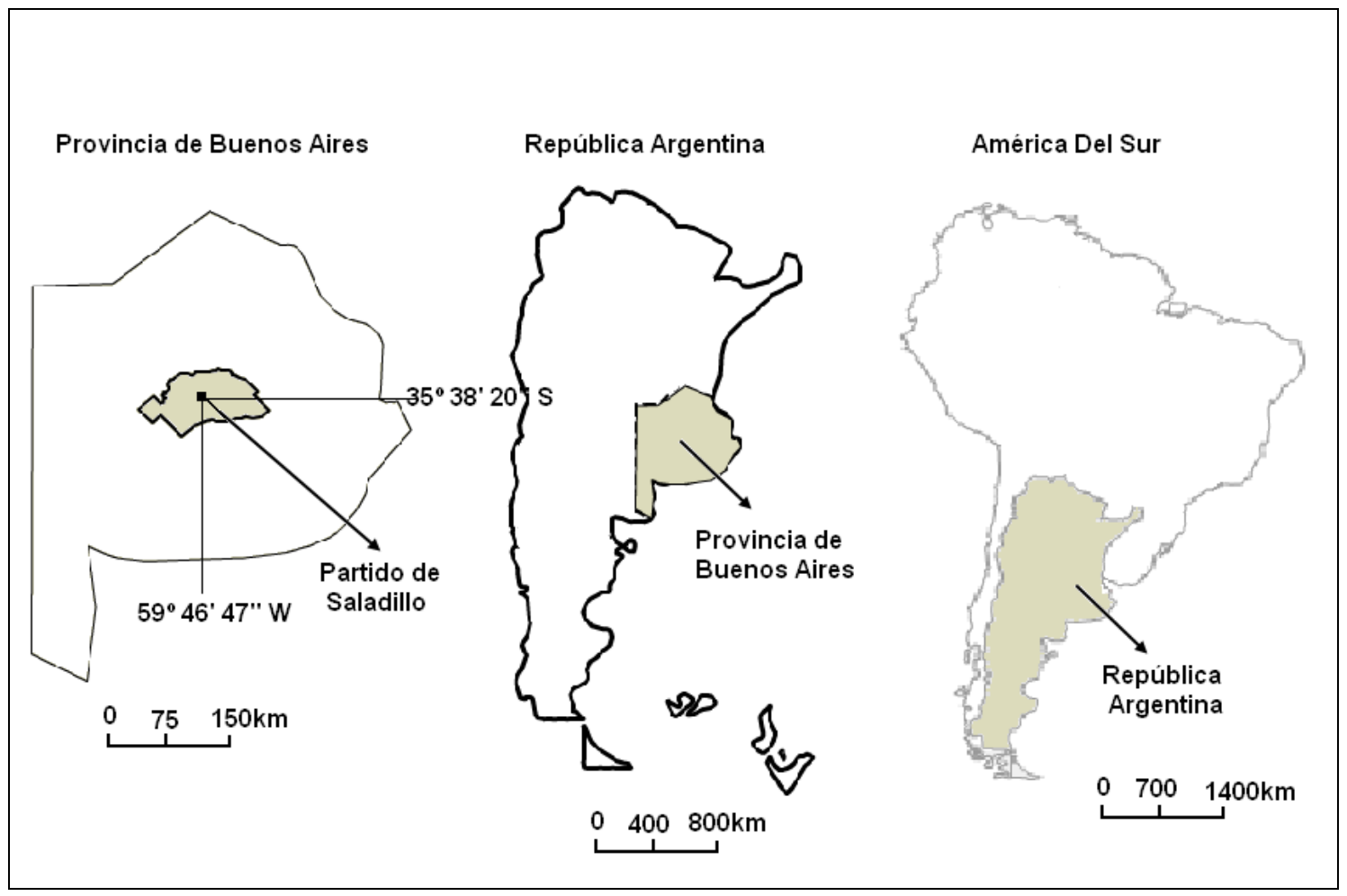

Fuente: Elaboración propia

Desde lo enunciado y a partir del marco teórico desarrollado a continuación, se realizó el trabajo de campo. Para el mismo se utilizaron, en un primer momento, técnicas 
cuantitativas (datos estadísticos) a partir de datos secundarios y técnicas cualitativas, como técnicas de análisis documental (de prensa/archivos públicos) para la recolección de datos secundarios; mientras que en un segundo momento, la indagación se realizó a través de técnicas cualitativas de autoinformación de observación directa y de entrevistas semi-estructuradas principalmente. Cabe aclarar, que las entrevistas fueron abiertas pero con un guión previamente estipulado que las conducía, y se dirigieron a informantes calificados (principalmente a delegados municipales y representantes de instituciones), ya que se consideró pertinente su aporte en la visión sobre las transformaciones territoriales y sociales debido a sus posiciones estratégicas en el tratamiento directo con la dinámica del territorio. El trabajo de campo fue llevado a cabo en el mes de noviembre del año 2011, en el cual se realizaron en total diez entrevistas: tres a delegados municipales, cuatro a representantes de instituciones y/o organizaciones y tres a pobladores.

La elección de esta metodología mixta a través de la triangulación científica de datos cuantitativos y cualitativos, responde a la riqueza y al potencial que produce esta estrategia metodológica al poder verificar y complementar la información en la etapa de análisis.

La elección del estudio de caso como medio de aproximación a la realidad tiene que ver con la convicción basada en la importancia que implica el acercamiento y el reconocimiento del objeto de estudio para un geógrafo y como consecuencia, en la riqueza que significa confrontar los contenidos adquiridos con las experiencias vividas en la realidad concreta de los espacios estudiados. Por tal motivo, se intentará reflejar los resultados de esta confrontación entre teoría y empírea, a partir de los aprendizajes, conclusiones, como así también nuevos cuestionamientos que el trabajo de campo realizado ha dejado como legado.

A continuación, se enuncia el marco teórico y se bosquejan algunos de los resultados que han surgido del análisis sólo del primer caso de estudio trabajado que se enmarca en una investigación más amplia y compleja, la cual pretende contemplar la dinámica de los ARM pertenecientes a cuatro subregiones bonaerenses. ${ }^{2}$ De todas maneras, la representatividad y pertinencia del caso seleccionado permite no sólo obtener explicaciones, sino que invita a "seguir pensando" en la complejidad del proceso de revitalización y retorno a lo rural.

\section{MARCO TEÓRICO}

El territorio modificado constantemente por redes está direccionado por la multiplicación de flujos entre nodos, es el medio en el cual se plasman las funciones más importantes que rigen la economía y la sociedad a escala local-global. Las transformaciones derivadas no son coyunturales sino mutaciones estructurales que se originan desde el régimen de acumulación fordista hacia una nueva forma, una nueva lógica del capitalismo actual identificado como posfordista, neofordista, sociedad informacional, entre otras designaciones.

\footnotetext{
${ }^{2}$ Este artículo se adscribe al proyecto "Aportes para el estudio de la identidad del espacio regional bonaerense desde el siglo XVIII hasta la actualidad. Territorio, historia, política y cultura". PICT- 20081150.
} 
En este escenario, la masiva incorporación de innovaciones está originando una ruptura con el anterior modelo, las nuevas tecnologías de la información se convierten en núcleos centrales del ciclo de acumulación y crece el peso del capital intangible respecto al del capital fijo antes dominante. La innovación al servicio de la economía hegemónica, produce transformaciones profundas que definen las nuevas realidades territoriales por medio de redes que posibilitan la competitividad y por lo tanto la acumulación $^{3}$. Como resultante, se identifican áreas innovadoras y bien conectadas, otras marginales o excluidas asociadas a una escasa o nula localización de capital transnacional y con deficiente acceso a los flujos globales. Para P. Veltz (1996) el problema es aprender a pensar el mundo de otro modo que como un mosaico de zonas, así el territorio se transforma en el eje principal para detectar y comprender las contradicciones producidas por el modelo.

De acuerdo a lo planteado, las conceptualizaciones dicotómicas urbano-rural, industrial-rural, agrícola-moderno, ciudad-campo; no son suficientes para explicar los cambios actuales y como lo afirma C. Grammont: “(...) los conceptos de análisis económicos y sociológicos de las escuelas neoclásicas, marxistas y neoliberales no pueden explicar los cambios actuales de los ER" (2008, p. 289).

El estudio de transformaciones territoriales a partir de los cambios en los vínculos urbano-rurales ha transitado un camino de continuidades y rupturas anclado en los debates científicos y políticos en torno al rol que los ER y los urbanos juegan en un proyecto de desarrollo territorial. Es productivo el estudio sobre el papel que "el campo" y "la ciudad" desempeñan en el desarrollo de las sociedades, pero son menos frecuentes los análisis del mismo desde un enfoque integrado, de las renovaciones que asumen los vínculos urbano-rurales en la construcción y re-construcción de cada territorio concreto, donde convergen procesos asociados a la nueva ruralidad y a la urbanización difusa.

Por ello, a la hora de examinar los ER, resulta necesario dejar en claro la preferencia por el abordaje sistémico, integral y territorial considerado desde la nueva ruralidad. Este enfoque deja de abordar los espacios rurales desde lo sectorial, como tradicionalmente lo hacía la geografía agraria, y plantea cómo los territorios abandonan su carácter autártico, centrado en estructuras agrícolas, para pasar a ser cada vez más determinados por vínculos urbanos-rurales, extraterritoriales, o en palabras de M. Santos (1996) por la interacción de verticalidades (lo global) y horizontalidades (lo local). El concepto de nueva ruralidad se ha desarrollado dentro de la discusión analítica del fenómeno de lo urbano-rural. Así para H. Ávila: “(...) la nueva ruralidad es la expresión de la reestructuración de los territorios rurales en el contexto de la globalización (...)" (2008, p. 97), en tanto para A. Riella y J. Romero (2003) no existe una nueva ruralidad sino más bien una mirada distinta sobre la vieja ruralidad.

A lo enunciado, se adscribe el concepto de multifuncionalidad, que posibilita visualizar y explicar la combinación de funciones y usos productivos y no productivos en relación a las recientes demandas de la sociedad urbana -desmitificando el protagonismo único o la monofuncionalidad de la actividad agrícola que ha pasado a desempeñar un nuevo papel a raíz del surgimiento de estos nuevos usos como el industrial, comercial, de recreo o esparcimiento y el residencial - con otros que se siguen desarrollando en los ER. Si bien esta perspectiva es reivindicada por algunos autores, también es criticada

\footnotetext{
${ }^{3}$ Por este tema se pueden consultar Camagni, M. y Gordillo, G. 2000; Castells, M. 1996; Méndez, R., 2002).
} 
por otros como J. A. Segrelles Serrano quien expresa: "La multifuncionalidad rural es una realidad conflictiva en la Unión Europea y es un mito en América Latina" (2007, p. 96).

De acuerdo a al abordaje sistémico, que prioriza la interpretación multiescalar, es decir, aquella en que las diferentes escalas, direcciones y contenidos de las articulaciones urbano-rurales trastocan la dinámica territorial, el territorio es considerado como construcción social y como tal sujeto al cambio y a la permanente reconstrucción (Entrena, 1998). En otras palabras, es la evolución global de las sociedades la que reconstruye permanentemente los espacios rurales para satisfacer sus necesidades (García Ramón, 1995). En este contexto, importa reconocer que el espacio no sólo es el trasfondo donde se dan estas transformaciones sino se convierte en producto en sí, un espacio consumible por sí mismo.

F. Entrena afirma: "La ruralidad como construcción social esta contextualizada en coordenadas temporales y espaciales especificas" (1998, p.76). Por lo tanto, el carácter mutante y circunstancial de lo rural hace necesario que los espacios rurales sean analizados a través de perspectivas histórico-procesuales. En la actualidad, en el marco de la creciente internacionalización económica propia del contexto de mundialización, resulta necesario reconocer la presencia de dos modelos que se conjugan y materializan en estos espacios reconfigurándolos a través de flujos tangibles e intangibles. Por un lado, los procesos de homogeneización y dependencia del modelo capitalista dominante, ligado a fenómenos de expulsión, deterioro y concentración, y por otro, los procesos de carácter emergente, como los nuevos usos que postula el modelo alternativo, dando lugar a nuevas territorialidades. (Nogar, 2008).

Así también, C. Pasciaroni, M. Olea y R. Schroeder hacen referencia a estos procesos que moldean la realidad de lo rural, y sostienen que como resultado se observa un escenario dual. Por un lado, áreas que se han especializados en producciones agrarias competitivas y por otro, áreas que se centran en actividades de compensación urbana. Los autores afirman: “(...) lo rural no sólo interesa como recurso agroganadero o forestal sino que también importa como ámbito de residencia y a los usos recreativos, turísticos y ambientales (...)" (2010, p. 2).

Como es habitual, los ER han sido caracterizados por las actividades de producción, principalmente agrarias que responden a criterios puramente económicos, pero paulatinamente se incrementan las actividades y los espacios de consumo bajo criterios económicos, sociales y ambientales, sobre todo alrededor de nuevos espacios de actividades de ocio y recreativas. "La relación campo-ciudad, la interacción urbano rural pone en marcha procesos de consumo y simultáneamente de producción de espacio" (Paniagua y Hoggart, 2002, p. 67). Estos autores emplean el concepto de idilio rural para explicar la atracción generalizada que ejercen los espacios rurales sobre las poblaciones urbanas en las modernas sociedades post-industriales. Una de las áreas temáticas con mayor utilización del concepto de idilio rural ha sido para explicar la contraurbanización o migración de población a áreas de baja densidad. Por otro lado, en esta estructura teórica no es posible desestimar el fenómeno de la segunda residencia definida como el instrumento de difusión y dispersión de la ciudad sobre el espacio rural, como la evidencia del proceso de rururbanización, el cual se refiere al aumento de migración de población urbana y de dinámicas metropolitanas a los antiguos espacios rurales (Gómez Contreras, 2010). 
Esta nueva dinámica de flujos internos entre los espacios rurales y urbanos hace tiempo viene siendo analizada desde la geografía británica, que desde mediados de los años 60' empezó a detectar signos de un reverso del éxodo rural. A partir de ese momento, este proceso ha sido tema de debate y ha despertado gran interés por la profundización de su estudio en otras regiones. Otros autores, han ensayado sobre el fenómeno de vuelta a lo rural desde el término contraurbanización; C. Ferrás, (2007) analiza este concepto y menciona que ya en 1976 B. Berry, desde el ámbito anglosajón, hacía referencia a la contraurbanización como una inversión de los flujos demográficos y económicos que ahora se presentaban en sentido descendente de los mayores a los menores, pero lo atribuía sólo a los sistemas de asentamientos de los países más desarrollados. Sin embrago, sostiene, que si bien en Latinoamérica es insuficiente la literatura académica que analice la contraurbanización, la región no se mantiene al margen de los cambios que la revolución tecnológica y la reestructuración productiva generaron en las formas de urbanización, por lo que la contraurbanización no debe atribuirse únicamente a los países desarrollados."La contraurbanización se encuentra presente en la mayoría de las sociedades del mundo occidental, tanto en Europa como en América, beneficiándose de ello determinadas áreas rurales que conocen un nuevo período de desarrollo económico y de crecimiento demográfico tras una fase oscura de declive" (Ferrás, 2007, p. 14) .

Por otro lado, A. Paniagua, (2008), también hace referencia al proceso de contraurbanización, pero va más allá en el debate al sostener la aparición de una nueva clase social en ciertos espacios rurales como consecuencia del retorno a lo rural, lo que otros autores denominan el proceso de elitización o gentrificación de lo rural, cuestión que aún no ha sido analizada para el caso de los espacios rurales latinoamericanos.

Como se observa en este marco introductorio, las discusiones acerca de las transformaciones de los espacios rurales, los vínculos urbanos-rurales y sus consecuencias en los ARM no es tarea culminada, sino que se encuentra en pleno proceso de construcción teórica.

\section{FLUJOS Y REDES QUE CAMBIAN. INDICIOS DE REVALORIZACIÓN DE LOS ESPACIOS RURALES}

"Campo y ciudad se encuentran hasta en el paisaje y en las condiciones de vida distintas, pero relacionadas y condicionantes de la sociedad global, puesto que la misma separación geográfica supone que una urbanización y un pueblo es un lazo de unión y relación de influencias mutuas" (Sánchez Jiménez, 1975, p. 145).

La elección de esta afirmación para comenzar no es casual sino que ha sido seleccionada por su grado de pertinencia y de profundidad. Cuando el autor hace referencia a “(...) lazo de unión y relación de influencias mutuas”, en otras palabras, se está hablando de los vínculos urbano-rurales sin los cuales no se podría entender ni explicar la realidad de los espacios rurales actuales. De todas maneras, es necesario dejar en claro que la intensidad, dinámica y direccionalidad de estos vínculos ha variado a lo largo de los años, de los contextos (Fordista y Posfordista) y de los territorios. Mientras que en el pasado hasta mediado de siglo XX, los débiles vínculos urbanosrurales se basaban únicamente en la venta de productos primarios a las ciudades, con el correr de los años, la autonomía de los espacios rurales fue disminuyendo por la entrada progresiva de flujos y acciones de actores sociales cada vez más ajenos a estos lugares. 
El crecimiento de las ciudades tanto físico, demográfico como económico, sumado a la expansión de los medios de comunicación, hizo que lo urbano haya ido extendiendo su alcance presionando y quebrando el aislamiento de los espacios rurales. Desde entonces, las relaciones de complementariedad entre lo urbano y lo rural nunca fueron simétricas sino que el proceso de urbanización significó la desruralización de la sociedad. Sobre este fenómeno, F. Entrena (1998), sostiene que la modernización se manifestó en el éxodo rural ligado a la consideración negativa de la ruralidad como paradigma de atraso y subdesarrollo, en contraste con el paradigma urbano industrial visto como símbolo de progreso y desarrollo. Claramente, la demanda de mano de obra para las industrias en las ciudades, sobre todo de trabajadores jóvenes, fue uno de las causas que generó por un largo período histórico una emigración constante de población del medio rural al espacio urbano.

Este artículo se enmarca en las últimas décadas, donde se manifiestan transformaciones sustanciales urbano-rurales. Mientras que los espacios rurales han experimentado adaptaciones como la pluriactividad y la agricultura de tiempo parcial como estrategias ante la expulsión de mano de obra asalariada que generó la mecanización y modernización productiva con fines productivistas cortoplacistas, en las ciudades, se evidencia que las ventajas de la aglomeración han encontrado un límite que se ve materializado en problemáticas de hacinamiento, degradación ambiental y conflictividad social. Por esta razón, autores como M. D. García Ramón, A. Tulla y N. Valdovinos afirman que "en las sociedades post-industriales el espacio rural ha sido revalorizado desde nuevas perspectivas: ambiental, cultural y paisajística" (1995, p. 31).

Por otro lado, tradicionalmente los espacios rurales latinoamericanos se enmarcaron entre dos lógicas de funcionamiento, una que responde a la racionalidad capitalista, priorizando el comercio internacional y por otro lado, aquella que busca la autosubsistencia bajo una lógica campesina. Paralelamente a los procesos de homogenización productiva, artificialización de los procesos productivos, flexibilización laboral, y profundización de la concentración de la tierra en manos de actores hegemónicos, el medio rural latinoamericano ha venido experimentando otros cambios importantes en lo que hace al uso del espacio, aunque sin abandonar su fuerte perfil agroexportador, que tiene que ver con usos no agropecuarios a través de nuevas actividades residenciales, de ocio y recreación.

La realidad de los espacios rurales en Argentina no es ajena a estos procesos sino que se hacen presentes dando lugar a una configuración heterogénea con áreas que alcanzan vinculaciones estratégicas de integración como núcleos dinámicos e innovadores, y por otro lado, áreas que profundizan su dependencia, reproduciendo su condición de territorios marginales, o peor aún, excluidos.

Esto hace necesario evitar todo tipo de generalizaciones en su análisis, y en su lugar, procurar hacer el ejercicio de identificar las dinámicas diferenciales que determinan su evolución desigual. Por esta razón, sin ignorar o desconocer que el despoblamiento y la desaparición de pueblos rurales es una realidad aún presente en el país- provocada entre otros factores por la reorganización del transporte ferroviario (desmantelamiento de estaciones, clausura de ramales y cese de las actividades concatenadas) desde mediados de la década de los años setenta del siglo XX y por la reciente mecanización y cientifización del trabajo rural- en este artículo se hará hincapié en la evolución y el 
proceso de revalorización de los espacios rurales a partir de las estrategias emergentes de los actores.

Según lo antes expuesto se propone una sencilla caracterización del universo de estudio.

El territorio de la provincia de Buenos Aires, sin considerar el Área Metropolitana de Buenos Aires y la Ciudad Autónoma de Buenos Aires, se encuentra dividido en 111 partidos que corresponden a jurisdicciones político administrativas de segundo orden. Dentro de la provincia se identifican diferentes subregiones, entre las cuáles se encuentra la Pampa Deprimida, caracterizada por ser una llanura sumamente plana que abarca prácticamente toda la cuenca del Río Salado y la del Arroyo Vallimanca, donde se ubica el partido de Saladillo. Como se puede observar en el mapa de la figura 2, el partido de Saladillo limita con cuatro distritos: Roque Pérez, Las Flores, General Alvear y 25 de Mayo.

Figura 2. División política de la provincia de Buenos Aires 


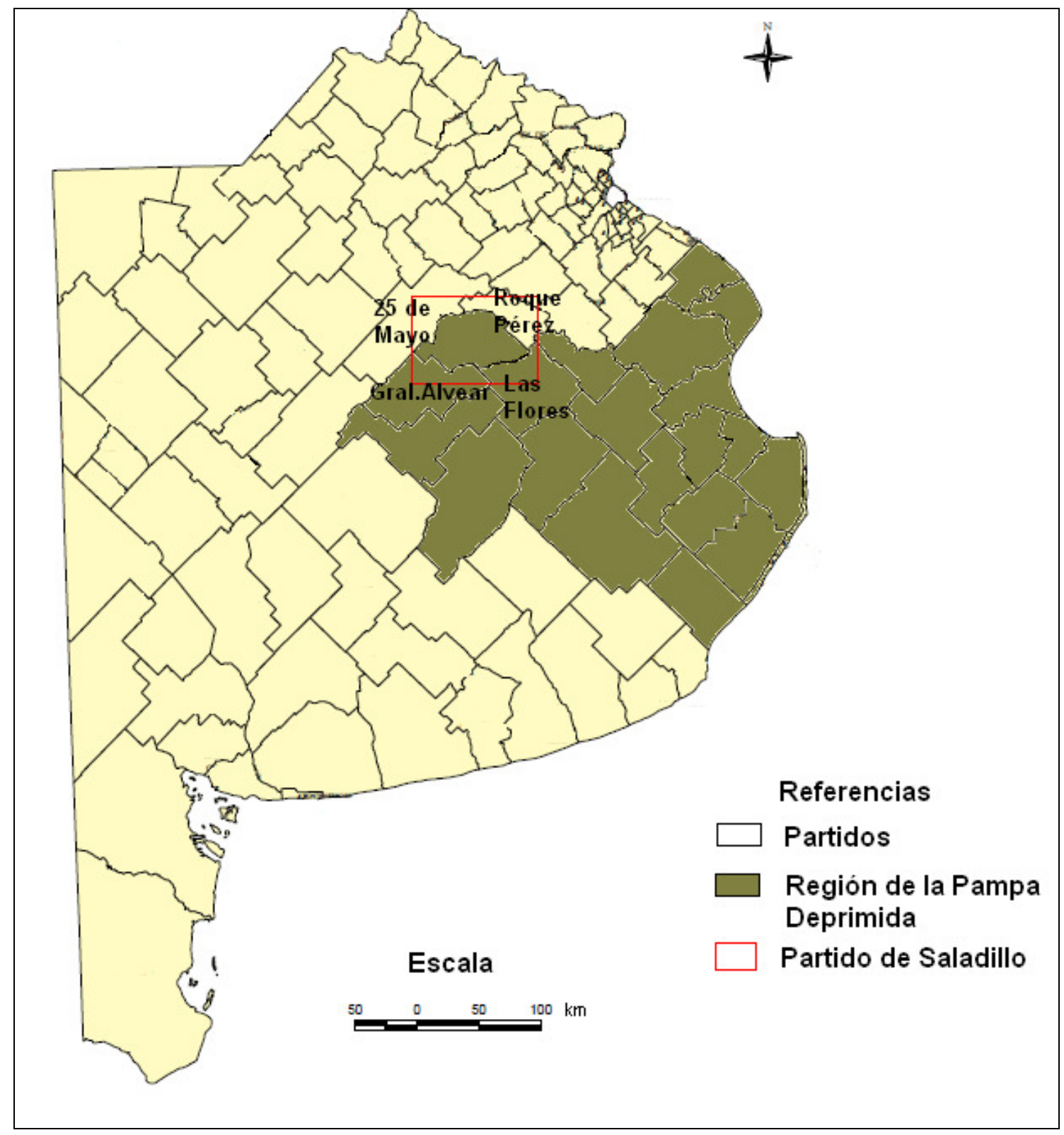

Fuente: Elaboración propia sobre el mapa político de la provincia de Buenos Aires extraído de http://www.gba.gov.ar

Saladillo junto al resto de los partidos que conforman la región de la cuenca deprimida bonaerense se caracteriza por un régimen pluviométrico anual que oscila de 1000 a 800 $\mathrm{mm}$. En general, estas lluvias cubren satisfactoriamente las necesidades del suelo, pero en la época invernal exceden las necesidades de los campos como consecuencia de la baja evapotranspiración más la existencia de una pendiente de muy bajo gradiente y la falta de una red de drenaje definida. Esto constituye una de las causas más importantes de la presencia de sequías e inundaciones. En estos suelos de baja fertilidad y aptitud potencial se desarrolla un pastizal natural que satisface las necesidades de una ganadería de bajos requerimientos, como es la cría de ganado de forma tradicional que se da junto a la nueva modalidad de la cría por engorde en los denominados feedlots.

El partido posee una estructura productiva mayormente agropecuaria y un sector industrial de mediano desarrollo. Durante los últimos años, se viene observando un 
crecimiento de las industrias metalmecánica, textil y del calzado pero sobre todo de la agroindustria. La industria alimenticia cuenta con la radicación de reconocidas empresas relacionadas al agro como Los GroboCopatel, Cargill, Profeed, Baya Casal, Compañía Argentina de Granos, entre otras.

El partido de Saladillo tiene una superficie de $2.685 \mathrm{~km}^{2}$ la cual forma parte de una extensa planicie llana aunque presenta ligeras ondulaciones interrumpidas al norte por el Arroyo Saladillo y al sur por el Arroyo Las Flores. La figura 3, muestra la superficie correspondiente al partido de Saladillo y los cuatro ARM seleccionados para el trabajo de campo. Estos asentamientos tienen origen a finales del año 1880 y principios de 1900 como estancias o parcelas de tierras que eran donadas por familias de alto poder adquisitivo para la construcción de estaciones ferroviarias. La llegada del tren imprimió un dinamismo que resultó clave para el crecimiento de estos poblados.

\section{Figura 3. Partido de Saladillo}

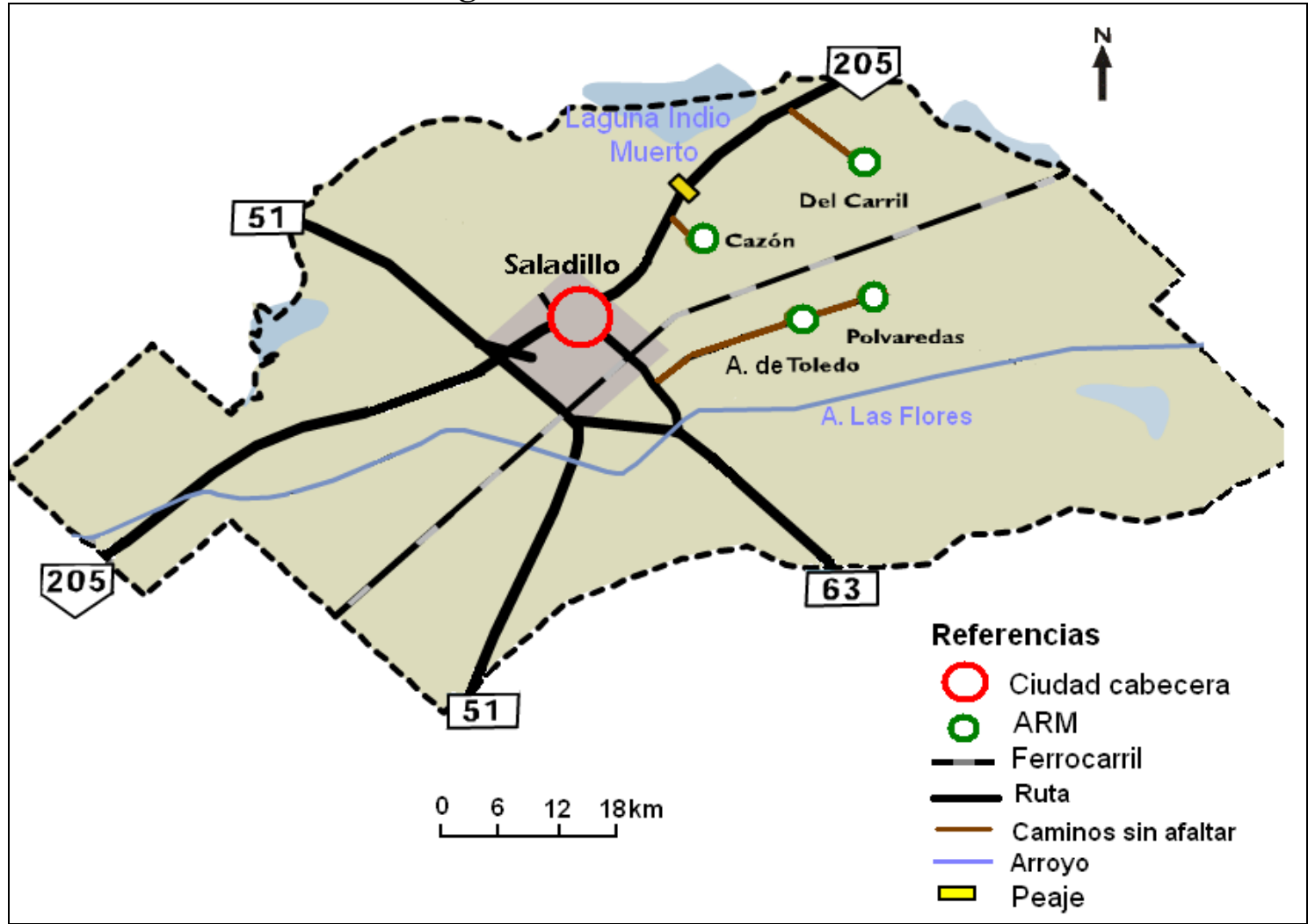

Fuente: Elaboración propia.

\section{Indicios del retorno a lo rural}

Si bien el análisis sobre el caso de estudio se basa principalmente en la identificación de fenómenos y procesos con el fin de explicar las transformaciones que se llevan a cabo, también resulta necesario considerar algunas variables cuantitativas que reflejan con datos concretos la realidad estudiada respaldando lo que los entrevistados afirman en sus relatos.

Una de las variables que resulta de gran interés para indagar el proceso de revalorización de lo rural es el crecimiento poblacional. A partir del cese del funcionamiento del ferrocarril que conectaba a estos pueblos con ciudades cabeceras de 
la provincia y como consecuencia, el deterioro de las actividades concatenadas con este medio de transporte, la variable de población empezó a perfilar un saldo negativo. Este saldo- que se va a mantener por muchos años- encuentra sus causas principalmente en la migración del los pobladores hacia las ciudades en busca de mejores oportunidades laborales.

En la actualidad, estudios recientes como el que realizado por C. Pasciaroni, M. Olea y R. Schroeder (2010) sobre la evolución de las localidades rurales argentinas de la región pampeana, sostienen, según el análisis de los datos censales del período 1991-2001, que la población rural dispersa tuvo una reducción cercana al $30 \%$, mientras que la población rural agrupada ${ }^{4}$ ha experimentado un crecimiento cercano al $12 \%$. Básicamente estos valores se explican por la influencia de los valores migratorios positivos que determinan la variable poblacional, lo que constituye una novedad ante la intensa emigración que por años padecieron los pueblos del interior.

Los datos del cuadro 1 muestran la variación intercensal de la población total del partido de Saladillo dejando en evidencia un saldo positivo que se viene sosteniendo desde los últimos cuatro censos. Además, se puede observar que los dos censos más recientes (2001 y 2010), presentan los mayores valores de variación relativa, llegando a casi un $13 \%$ para el año 2001.

A continuación, el cuadro 2 agrega información sobre la cantidad de viviendas censadas en el partido para el año 2001 y 2010, mostrando un crecimiento tanto en viviendas (local dispuesto para fines de alojamiento de personas) como en hogares (unidad socioeconómica formada por individuos que viven juntos en la misma vivienda $\mathrm{y}$ conforman una unidad de consumo).

El cuadro 3, refleja los datos de población de los cuatro ARM del partido analizado, a partir del cual se puede percibir una incipiente recuperación de la población en tres de ellos, exceptuando Álvarez de Toledo, asentamiento que no aumenta su población pero que la mantiene. Del Carril es el asentamiento que presenta mayor crecimiento de población. Aunque no se cuenta con el valor de población que arroja el último censo, es de suponer que el aumento continúe. Particularmente, la presencia de Cargill, Compañía Argentina de Granos instalada desde el año 2003 en Del Carril ha significado en los últimos años el motor para el crecimiento de este asentamiento, sobre todo por las inversiones llevadas a cabo en el lugar y el empleo de mano de obra en la planta como en las actividades vinculadas a ésta. Este hecho, es decir, la existencia de fuente de trabajo se convierte en un eficaz factor de atracción de población.

Cuadro 1. Evolución de la población total del partido Saladillo, 1960-2010

\begin{tabular}{|c|c|c|c|c|c|c|}
\hline & $\mathbf{1 9 6 0}$ & $\mathbf{1 9 7 0}$ & $\mathbf{1 9 8 0}$ & $\mathbf{1 9 9 1}$ & $\mathbf{2 0 0 1}$ & $\mathbf{2 0 1 0}$ \\
\hline Población & 23.554 & 23.214 & 24.727 & 26.200 & 29.600 & 32.103 \\
\hline Variación relativa & $-4,21 \%$ & $-1,44 \%$ & $+6,51 \%$ & $+5,95 \%$ & $+12,97 \%$ & $+8,45 \%$ \\
\hline
\end{tabular}

Fuente: Instituto Nacional de Estadísticas y Censos, INDEC.

\footnotetext{
${ }^{4}$ Población rural que vive en agrupamientos de menos de 2.000 habitantes.
} 
Cuadro 2. Cantidad de viviendas y hogares en el partido de Saladillo

\begin{tabular}{|c|c|c|}
\hline & $\mathbf{2 0 0 1}$ & $\mathbf{2 0 1 0}$ \\
\hline Viviendas & 11.601 & 13.370 \\
\hline Hogares & 9.347 & 10.768 \\
\hline
\end{tabular}

Fuente: Instituto Nacional de Estadísticas y Censos, INDEC.

Cuadro 3. Evolución de la población de los pueblos del partido de Saladillo, 1991-2010

\begin{tabular}{|c|c|c|c|}
\hline \multicolumn{4}{|c|}{ Cantidad de población } \\
\hline & $\mathbf{1 9 9 1}$ & $\mathbf{2 0 0 1}$ & $\mathbf{2 0 1 0}$ \\
\hline Del Carril & 1.146 & 1.228 & $*$ \\
\hline Polvaredas & 376 & 413 & $*$ \\
\hline Cazón & 283 & 240 & $*$ \\
\hline Alvarez de Toledo & 232 & 232 & $*$ \\
\hline
\end{tabular}

Fuente: INDEC. Censo Nacional de Población, Hogares y Viviendas.

*Los datos aún no han sido procesados

Del último censo la información obtenida sobre el listado de viviendas de las localidades del interior indicó: en Cazón hay 110 viviendas particulares; en Polvaredas hay 205 viviendas particulares y 1 en construcción sin techo; en Del Carril son 557 las viviendas particulares, 2 las viviendas colectivas y 17 construcciones sin techo, mientras que en Álvarez de Toledo hay 126 viviendas particulares y 3 sin techo.

Otro indicador que merece ser analizado por los cambios que presenta, es el valor de los terrenos, es decir, las cotizaciones del mercado inmobiliario. Un entrevistado expresó:

"Un terreno hace 10 años atrás valía $\$ 1000$ (de 27 x 68 mts.).Antes no valía la pena venderlos, hoy valen $\$ 45$ ó $50000 \ldots$ hay que reconocer que tomaron valor" (DELEGADO MUNICIPAL DE POLVAREDAS).

El dato que arroja esta cita invita a pensar las causas que provocan tal aumento en la cotización de los terrenos. Según L. M. Gómez Contreras (2010), son dos procesos los que intervienen en este cambio significativo, uno materializado a partir de la iniciativa privada individual y el otro gestionado desde las empresas inmobiliarias, cuyo objetivo es la explotación turística del territorio relacionado con los atributos tales como buenas vías de acceso, lugares aledaños a la ciudad, patrimonio, seguridad y contacto con la naturaleza, entre otros. 
Sin duda, la llegada de nuevos pobladores y su demanda residencial presiona sobre el mercado de la vivienda generando un alza en los precios de los inmuebles. Este factor de cambio como consecuencia, puede inducir efectos contradictorios sobre la propia población local, ya que si bien se revalorizan las viviendas, se podría dificultar la compra para la localización de las nuevas generaciones. Este fenómeno, por el cual los jóvenes deben emigrar, ya ha tenido lugar en algunos espacios rurales de países desarrollados tal como lo expresa la siguiente cita: "La creciente presión de la demanda ha elevado los precios y, en este sentido, no es de extrañar que se hayan generado en numerosos casos conflictos con la población autóctona que observa cómo el acceso a la vivienda es cada vez más difícil para ellos, en contraposición a la mayor capacidad de compra que muestran los grupos de población que se instalan en áreas rurales" (Solana, 2006, p. 61). Como sostiene este autor, la revalorización de los lotes por el aumento de la demanda trae aparejado un conflicto para la población del lugar y puede llegar a convertirse en uno de los factores que empujan a los jóvenes a desplazarse hacia otros espacios de menor valor inmobiliario. Este hecho provoca un desenlace incierto que deberá ser profundizado a través de diferentes análisis, desde diferentes variables y en diversos universos.

Por otro lado, se observa que este proceso de vuelta a lo rural no se da sin conflictos, ya que los lugareños se expresan de diversas formas respecto a estos nuevos habitantes. Cuando ven este proceso de revalorización y retorno de población a sus pueblos lo perciben como algo ajeno a ellos, como un desarrollo independiente del resto del pueblo, como algo impuesto. En relación a esto, F. Entrena (1998) sostiene para el caso español, que mientras una considerable parte de la población urbana tiende a identificarse con imágenes positivas de la ruralidad, los campesinos y agricultores suelen percibir negativamente la presente situación. En el caso de estudio, una de las entrevistas también dejó en evidencia este conflicto:

"Nuevos contados. Los que vienen son gente que compra, los que se hacen una casa de fin de semana y están viernes, sábado y domingo. Y eso ¿No tiene ningún impacto en el pueblo? No, ninguno. Sólo compran algo de mercadería los días que están y algunas plantas para mejorar las quintas que compran" (POBLADOR DE CAZÓN).

Siguiendo con este análisis, M. Solana en relación a este problemática plantea: "La recuperación de los pueblos pero sin el desarrollo de un tejido social convierte a pueblos de fin de semana pero que están muertos el resto del tiempo. Eso hace que se corra el riesgo de originar cierta museización de los pueblos y de la vida supuestamente rural. La creación de pueblos de postal, de gran belleza pero abandonados gran parte del año y destinados servir de escenario para el ocio y el descanso" (2006, p. 81). Sin embargo, sin querer relativizar este planteo, no se puede dejar de pensar la otra posibilidad, que las familias que visitan esporádicamente los espacios rurales a partir de las residencias de fin de semana puedan llegar a instalarse progresivamente y significar un cambio importante en la estructura demográfica tradicionalmente envejecida de los espacios rurales. Existiría en ese caso la posibilidad de rejuvenecimiento de la pirámide poblacional con la presencia de niños y a la vez, se generarían nuevas actividades relacionadas a servicios que estas familias demandarían para localizarse y vivir. En relación a esto, los tres delegados municipales de los pueblos rurales entrevistados, dejaron en claro que ya se hacen presente las nuevas demandas de servicios, tanto en materia de salud, como de educación, tendido eléctrico, gas natural, recolección de residuos y pavimentación. Este dato también es relevante, ya que permite percibir la 
presencia de nueva población que se instala en estas localidades como así también, crea mejores condiciones para atraer nuevos flujos de población.

Las siguientes dos citas, hacen alusión a la presencia de población nueva en el ARM de Polvaredas:

"Se ha ido gente del campo, hay taperas en el campo, hay chacras que no hay gente, pero en el pueblito en pocos años ha aumentado en unas 40 viviendas, que para los que es el pueblo es bastante" (POBLADOR DE POLVAREDA, 82 AÑOS).

"La gente del campo se viene al pueblo, gente de la ciudad que había nacido en el campo se están volviendo al pueblo. Hubo un cambio. Hay 10 familias nuevas y 40 casas de familia nuevas, de las cuales la mitad son de fin de semana... Los que se están instalando en Polvaredas son paraguayos que se emplean en criaderos de pollo. Se ubicaron 1 ó 2 familias y éstas están trayendo a otras. En tres criaderos hay familias paraguayas. Vienen sin vivienda y le dan vivienda la gente del criadero" (DELEGADO MUNICIPAL DE POLVAREDAS).

El análisis de los datos que arrojan estas dos citas permite dilucidar tres procesos que influyen en el aumento de población en los ARM.

En primer lugar, el proceso de disminución de población rural dispersa en los espacios rurales, el cual encuentra sus causas en desaparición de explotaciones agropecuarias ligado a la concentración de tierras en manos de actores como los pooles de siembra, la homogenización productiva que obliga a los productores a arrendar sus tierras o a redireccionar sus producciones a la producción de comodities, y a la mecanización productiva que reduce la mano de obra empleada en las explotaciones.

En segundo lugar, la fuerte tendencia a la construcción de casas de fin de semana, la cual responde básicamente a la demanda específica de la población urbana de un nuevo uso residencial, de ocio o ambiental. En otras palabras, se puede afirmar que se está en presencia del fenómeno de segunda residencia, elemento que explica en gran parte la dinámica económica, el mercado de la vivienda y la aparición de diversos conflictos en el ámbito rural. (Solana, 2006). En la fotografía 1, se puede observar una de las tantas viviendas en construcción en Polvaredas, escena que se repitió en los cuatro ARM visitados.

M. D. García Ramón, A. Tulla y N. Valdovinos explican: "Frente a la relocalización permanente de la población urbana aparece la urbanización estacional, tanto en forma de viajes puntuales como de veraneo en residencias secundarias" (1995, p. 72). Entre los aspectos que caracterizan la segunda residencia, menciona:

1) El uso temporal de la vivienda en forma estacional, periódica o esporádica.

2) El lugar donde se construye (generalmente con atractivos paisajísticos o aptos para el descanso).

3) El motivo del uso (disfrute de vacaciones, fines de semana, en definitiva, el ocio).

4) El buen acceso (garantía del uso fácil y frecuente). 
La creciente disociación del territorio con la actividad económica, es decir, entre lugar de residencia y de trabajo, también es uno de los factores que pueden ayudar a explicar esto fenómeno. La población que se instala en estos pueblos, tiene la característica de estar a pocos kilómetros de ciudad de Saladillo con lo cual el traslado diario a sus lugares de trabajo está garantizado.

\section{Fotografía 1. Nueva vivienda en construcción en Polvaredas}

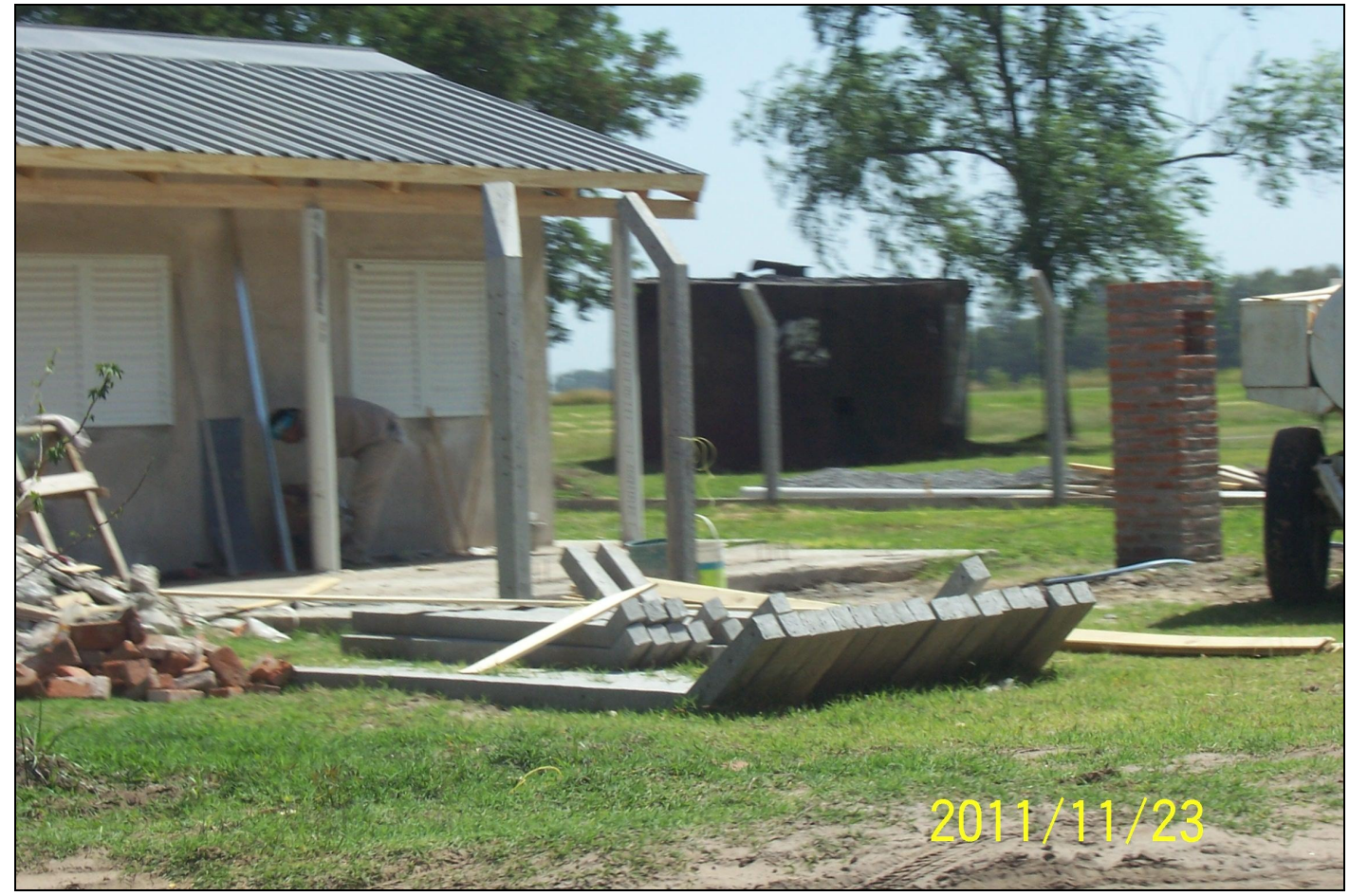

Autora: Luciana Clementi (Noviembre del 2011 en Polvaredas, partido de Saladillo).

M. Solana (2006) expresa que en los estudios de casos desarrollados en España, la población que vive esta experiencia corresponde a profesionales y a personal de alta y media cualificación en gran parte del sector servicios, las cuales deben conjugar su deseo de vivir en áreas rurales con la dificultad de encontrar empleo en ellas, por su perfil profesional. El estudio de caso en Saladillo no permite dar por sentado esta cuestión pero si se convierte en un futuro tema a profundizar.

En tercer lugar, resulta necesario considerar la presencia de población extranjera en los espacios rurales, fenómeno que se dio en la antigüedad marcando la historia del país a partir de la llegada de inmigrantes sobretodo europeos en busca de tierras para poder trabajarlas, ahora parece repetirse pero en contexto totalmente diferente y con una nueva modalidad. En este caso, se hace mención a la llegada de población limítrofe de nacionalidad paraguaya, que se localiza en el ARM de Polvaredas empleada en criaderos de pollo y según otros entrevistados, en lo que es albañilería, convirtiéndose en una competencia ante los pobladores porque ofrecen su trabajo a cambio de bajas remuneraciones. El cuadro 4 muestra la presencia de población extranjera en el partido de Saladillo de acuerdo con los datos del último censo (2010) según el país de 
nacimiento, el sexo y la edad. En él se puede observar la fuerte presencia de población de nacionalidad paraguaya, tanto masculina como femenina y sobre todo jóvenes y adultos.

Cuadro 4. Provincia de Buenos Aires, partido Saladillo. Población total nacida en el extranjero por lugar de nacimiento, según sexo y grupo de edad. Año 2010

\begin{tabular}{|c|c|c|c|c|c|c|c|c|c|}
\hline \multirow{3}{*}{ Lugar de nacimiento } & \multirow{3}{*}{$\begin{array}{l}\text { Población } \\
\text { total } \\
\text { nacida en } \\
\text { el } \\
\text { extranjero }\end{array}$} & \multicolumn{8}{|c|}{ Sexo y grupo de edad } \\
\hline & & \multicolumn{4}{|c|}{ Varones } & \multicolumn{4}{|c|}{ Mujeres } \\
\hline & & Total & $\begin{array}{l}0- \\
14\end{array}$ & $\begin{array}{c}15- \\
64\end{array}$ & $\begin{array}{l}65 \text { y } \\
\text { más }\end{array}$ & Total & $\begin{array}{l}0- \\
14\end{array}$ & $\begin{array}{c}15- \\
64\end{array}$ & $\begin{array}{l}65 \text { y } \\
\text { más }\end{array}$ \\
\hline Total & 536 & 276 & 55 & 183 & 38 & 260 & 41 & 183 & 36 \\
\hline AMÉRICA & 436 & 227 & 48 & 169 & 10 & 209 & 37 & 164 & 8 \\
\hline Países limítrofes & 421 & 222 & 47 & 165 & 10 & 199 & 33 & 158 & 8 \\
\hline Bolivia & 15 & 6 & 1 & 4 & 1 & 9 & - & 9 & - \\
\hline Brasil & 9 & 6 & - & 6 & - & 3 & - & 3 & - \\
\hline Chile & 23 & 9 & - & 9 & - & 14 & 3 & 8 & 3 \\
\hline Paraguay & 337 & 182 & 46 & 130 & 6 & 155 & 29 & 123 & 3 \\
\hline Uruguay & 37 & 19 & - & 16 & 3 & 18 & 1 & 15 & 2 \\
\hline Países no limítrofes & 15 & 5 & 1 & 4 & - & 10 & 4 & 6 & - \\
\hline Perú & 8 & 2 & 1 & 1 & - & 6 & 1 & 5 & - \\
\hline Resto de América & 7 & 3 & - & 3 & - & 4 & 3 & 1 & - \\
\hline EUROPA & 94 & 46 & 6 & 14 & 26 & 48 & 3 & 18 & 27 \\
\hline Alemania & - & - & - & - & - & - & - & - & - \\
\hline España & 35 & 18 & 3 & 6 & 9 & 17 & 3 & 3 & 11 \\
\hline Francia & 3 & 3 & - & 1 & 2 & - & - & - & - \\
\hline Italia & 40 & 17 & 1 & 2 & 14 & 23 & - & 8 & 15 \\
\hline Resto de Europa & 16 & 8 & 2 & 5 & 1 & 8 & - & 7 & 1 \\
\hline ASIA & 6 & 3 & 1 & - & 2 & 3 & 1 & 1 & 1 \\
\hline China & - & - & - & - & - & - & - & - & - \\
\hline Corea & - & - & - & - & - & - & - & - & - \\
\hline Japón & 1 & 1 & - & - & 1 & - & - & - & - \\
\hline Líbano & 2 & 1 & - & - & 1 & 1 & - & - & 1 \\
\hline Siria & 1 & - & - & - & - & 1 & - & 1 & - \\
\hline Taiwán & - & - & - & - & - & - & - & - & - \\
\hline Resto de Asia & 2 & 1 & 1 & - & - & 1 & 1 & - & - \\
\hline ÁFRICA & - & - & - & - & - & - & - & - & - \\
\hline OCEANÍA & - & - & - & - & - & - & - & - & - \\
\hline
\end{tabular}

Fuente: INDEC. Censo Nacional de Población, Hogares y Viviendas 2010.

Nota: Se incluye a las personas viviendo en situación de calle. 
A partir de este dato, se puede llegar a pensar que la llegada de población extranjera al país en busca de mejores condiciones de vida no se limita sólo al ámbito urbano (principales centros urbanos) sino que es un proceso que se está extendiendo también hacia los espacios rurales. Este hecho se convierte en un puntapié para seguir analizando este fenómeno como un indicio más en el estudio del retorno rural.

\section{Factores que inducen el re poblamiento de los espacios rurales}

El eje globalización-territorio-crisis rural-nuevos usos se ha convertido a lo largo de los últimos quince o veinte años en un tópico de reflexión constante. Esta diferente posición que ocupan los espacios rurales se observa en espacios institucionalizados pero también en otros ámbitos "alternativos". Por su parte, su centralidad "alternativa" puede observarse en la configuración de ciertos movimientos cuasi-neorrománticos que pululan en distintos países europeos y en los estados unidos, postulando "una vuelta al campo" (Nogué i Font, 1988).

Así los espacios rurales dejan de ser considerados unánimemente como el espacio que sustenta la producción de alimentos, tal como se lo veía hasta no hace mucho tiempo. Hoy se los concibe (y percibe) como ámbitos de múltiples actividades, entre las cuales la producción alimenticia en su primera fase es sólo una más, quizás aún la más importante, pero no ya la única.

Paralelamente a estos procesos, el desenvolvimiento de la vida urbana generó en una gran parte de sus habitantes una sensación de agobio, de asfixia, de desnaturalización del medio y de la vida en sí misma. Los urbanistas de generaciones de urbanistas empezaron a sentirse encerrados en su "espacio natural"; simultáneamente, los urbanistas de generaciones de rurales mantenían fresca la memoria colectiva de su "espacio natural". El deseo de unos y la añoranza de otros no tardó en confluir en un movimiento ideológicocultural de revalorización de lo rural. Los primeros, buscando una arcadia mítica; los segundos, procurando rescatar su arcadia perdida.

En poco tiempo, la sociedad en su conjunto hizo suyos aquellos planes y esta ideología cultural. El campo comenzó a ser re-visitado conceptualmente, se lo revalorizó; se lo presentó como un repositorio de valores que la sociedad industrial olvidó o destruyó. Lo natural, lo auténtico, lo puro o lo personal serían algunos de los factores que sólo podrían hallarse en el medio rural.

Resulta clave preguntarse cuáles son las causas o los factores que producen este fenómeno de atracción nuevamente hacia lo rural, o bien cuáles son los factores expulsores que se dan en el ámbito urbano y que comienzan a revertir la tendencia de las migraciones internas campo-ciudad.

El sociólogo francés B. Hervieu (1997) reconoce algunas de las transformaciones exógenas que hicieron al espacio rural atractivo. Entre ellas se puede mencionar:

1) La movilidad social: En relación a la capacidad de movilidad de población resulta clave el papel del automóvil en los procesos de urbanización de los espacios rurales, ya que permite, a través de las infraestructuras viales, extenderse a pueblos rurales próximos a las ciudades grandes o medias y no limitarse únicamente al margen o alrededores de los espacios metropolitanos. De manera que, no se puede pensar el 
fenómeno puntual de la segunda residencia en otro momento histórico, ya que resulta imposible disociar éste proceso con el del desarrollo de los medios de transporte como el automóvil y de las infraestructuras viales, caminos, rutas, carreteras o autopistas. "Un área bien dotada de equipamientos e infraestructuras favorece la implantación de residencias secundarias y el crecimiento de éstas exige mejores instalaciones". (López, 2003, p.72). En el caso trabajado, se observa una vinculación de los pueblos rurales con la ciudad cabecera de Saladillo a través de vía pavimentada y caminos de tierra en otros tramos. Esto resulta desfavorable para la fluidez de los vínculos, además, no existe un transporte público sino que los traslados están a cargo de un servicio privado el cual ofrece diferentes frecuencias diarias para el transporte de pasajeros.

2) Relación estilo de vida ligada a la naturaleza: La tendencia a la revalorización de la naturaleza frente a los aspectos poco saludables de la congestión en las urbes. Esto se puede observar en las siguientes citas:

"Ahora últimamente, la nueva modalidad es que mucha gente se viene a instalar a los pueblos del interior desde afuera (principalmente de la capital federal). Está resurgiendo otra vez instalarse, pero no productores del lugar sino gente que lo están usando como un lugar para fin de de semana, por ser pintorescos, tranquilos, por la vida con la naturaleza. Por eso otra vez están reflotando" (SECRETARIO DE PRODUCCIÓN DEL MUNICIPIO DE SALADILLO).

"Cuando funcionaba el ferrocarril había muchísimos comercios... después que se fue el ferrocarril desapareció todo, la gente se fue a Saladillo. Ahora está pasando que la gente que vivió acá (gente mayor) está queriendo volver a su lugar. Hay mucha demanda de lotes, están haciendo casitas de fin de semana, la gente que tenía pertenencias las están reconstruyendo y buscando un lugar de descanso, porque es un lugar muy tranquilo...se vive bien" (DELEGADA MUNICIPAL DE ÁLVAREZ DE TOLEDO).

La búsqueda de condiciones contrarias al estrés de la urbanización: paz, tranquilidad, seguridad, etc. es la que puede llegar a suponer que un gran porcentaje de la población que emigra de la ciudad al campo es de edad avanzada ya retirada de su profesión. Pero en general, la emigración estacional de población de clase media a los espacios rurales tiene que ver con los valores y aspectos que hacen a formas de vida más saludables a las que viven semanalmente en la ciudad.

F. Entrena hace referencia a esta cuestión afirmando: "En nuestros días se ha producido una superación histórica de las condiciones que daban lugar a esa imagen de la ruralidad en las sociedades tradicionales" (1998, p. 81). Las apelaciones al reencuentro con la naturaleza, a la armonía con el tiempo, a la calidad de la vida y al respeto del medio ambiente manifestadas a través de las nuevas imágenes de la ruralidad evidencian la crisis de la idea de progreso continuo y sin limites que alentaron los procesos de industrialización, modernización y urbanización durante los siglos XIX y XX”.

M. D. García Ramón, A. Tulla y N. Valdovinos (1995) agregan, en relación a los posible motivadores de este proceso, que tanto el precio relativamente bajos de los terrenos, la existencia de una relación familiar entre antiguos propietarios y los actuales, el nivel de ingresos disponible de los demandantes para invertir, la existencia de grandes espacios junto a áreas muy densamente pobladas, como la planificación pública o promoción privada de grupos, han sido aspectos decisivos. En relación a estos posibles motivadores en el caso analizado si se puede constatar los bajos costos que tenían los 
terrenos (aunque en la actualidad comiencen a aumentar por la demanda), pero no la planificación por parte de instituciones públicas, las cuales tratan de responder a las transformaciones que comienzan a darse pero no las impulsan.

\section{CONSIDERACIONES FINALES}

En la actualidad, los espacios rurales ya no pueden ser considerados sólo como espacios de producción de comodities, sino que las redes tangibles e intangibles que los atraviesan obliga a considerarlos cada vez más como espacios heterogéneos, dinámicos, y con potencialidades o capacidades ocultas que merecen ser reconocidas. Sin embrago, los signos de revalorización de lo rural tienen lugar de manera paralela a una creciente agudización de la sensación de crisis de sus habitantes. Si bien, no se debe ignorar el evidente declive, deterioro y los fenómenos de exclusión que algunas áreas rurales aún siguen generando, tampoco se debe dejar de reconocer los signos de reactivación y los procesos emergentes positivos de otras.

Por lo tanto, este trabajo no pretende eludir la realidad de la disminución de la población activa agraria que aún sigue siendo significativa en las áreas rurales, sino a partir de esta realidad, considerar también aquellas situaciones inversas que se están empezando a dar de forma paralela.

Los resultados del trabajo trajeron a la luz nuevas funciones de los espacios rurales. Específicamente, se divisan ciertos indicios que marcarían el comienzo de un incipiente retorno a lo rural como consecuencia de los procesos que activan los vínculos urbanorurales como estímulos de una revalorización de lo rural, y que pueden a llegar a ser considerados futuros ejes de desarrollo territorial.

Por muchos años se difundió la correspondencia entre urbanización, industrialización y desarrollo, la cual reforzó la idea que lo rural tarde o temprano debía ser vaciado por el éxodo de población hacia las ciudades. En los últimas décadas, la emigración de la cuidad al campo de población jubilada y la emigración estacional de familias a residencias secundarias anuncian signos de repoblación. Concretamente, la creciente demanda residencial sobre los espacios rurales, invita a replantear el olvido y la visión simplificadora de los espacios rurales por una más acorde a la nueva realidad.

Esta nueva dinámica imprime transformaciones en los espacios rurales que abren incertidumbres futuras como:

a) Si el uso temporal de estos espacios y la compra de segundas residencias es un paso previo a la posterior instalación definitiva.

b) Si el incremento progresivo del precio de la vivienda en estas áreas rurales puede llegar a provocar una mayor emigración, sobre todo de los jóvenes que encuentran grandes dificultades para adquirir una vivienda, y en consecuencia, el espiral de emigración y despoblación continuaría dificultando el proceso de reemplazo generacional.

c) Si la recuperación de los pueblos, pero sin el desarrollo de un tejido social, convierte a las localidades en pueblos de fin de semana pero que están muertos el resto del tiempo. 
Ante estas incertidumbres será necesario analizar cuál es el papel que cumple el Estado como actor social en el desarrollo de políticas públicas para gestionar estos territorios ante las transformaciones que vienen experimentando. Será precisa la intervención de las autoridades estatales llevando a cabo planes de ordenación territorial que establezcan usos claros de los espacios rurales.

Lo expuesto sobre el caso de estudio abre la posibilidad de estudiar los espacio rurales desde un enfoque integral desde el cual se identifica a los espacios rurales como multifuncionales, es decir, espacios que comienzan a combinar la función productora de alimentos con otras actividades que garantizan la conservación del medio natural y la mejora de las condiciones de vida y trabajo de la población rural. Para que esto no sea sólo un deseo o se quede en sólo indicios, sino que sea una realidad que se consolide, será necesario resolver ciertos problemas estructurales como circunstanciales que se hacen presentes en los espacios rurales latinoamericanos como la concentración de la tierra, la marginación del pequeño agricultor y el predominio de los modelos agroexportadores. En relación a esta situación, J. A. Segrelles sostiene: "Esta deseable multifuncionalidad agrorrural puede convertirse en un mito inalcanzable si no se solucionan antes los verdaderos problemas que obstaculizan el desarrollo positivo del campo latinoamericano: las estructuras agrarias tradicionales y los seculares desequilibrios, injusticias, desigualdad y pobreza que aún caracterizan a estos espacios no urbanos" (2007, p. 24).

Ante lo expuesto, se debe reconocer que la actual vuelta a lo rural no debe ser concebida como un retorno al pasado tradicional campesino, sino que debe ser entendida más como la búsqueda de un ámbito de vida o espacio de ocio/residencia que un espacio de producción.

A modo de conclusión, se puede afirmar que los espacios rurales están reconstruyendo su imagen a través de la definición de sus escenarios y desafíos, por ello resulta oportuno hablar de territorios rurales en mutación adaptativa crítica, es decir, escenarios en donde la tensión fragilidad-revitalización adquiere diversas formas de resolución territorial. La visualización y estímulo de las trayectorias analizadas, el conocimiento de la diversificación de usos y de acciones, el abordaje de los ER en forma integrada a los espacios urbanos; son ejes fundamentales para comprender y proyectar. Por lo que, el escenario analizado ilustra nuevas relaciones y articulaciones emergentes de nuevos grupos sociales, exponentes de valores post-modernos y post-productivistas y además, materializan acciones resultantes de la imbricación entre lo local y lo global. Las redes emergentes dan luz no sólo a los vínculos urbano-rurales sino a la multifuncionalidad de los ER; a las relaciones entre los actores rurales y a los procesos transversales de grupos sociales que demandan recursos tangibles e intangibles. Este entramado no presenta una naturaleza simple o lineal, no se adscribe a un modelo estructurado y conocido, sino que son redes complejas sostenidas por nuevas necesidades y nuevas relaciones espacio-temporales que merecen seguir siendo analizadas. 


\section{BIBLIOGRAFÍA}

ÁVILA SÁNCHEZ, H. Enfoques geográficos en torno a la nueva ruralidad. En PÉREZ, E., FARAH, M. y CARTÓN DE GRAMMONT, H. La nueva ruralidad en América Latina. Avances teóricos y evidencias empíricas. Bogotá: Pontificia Universidad Javeriana y CLACSO, 2008, p. 103-132.

CARTÓN DE GRAMMONT, H. El concepto de nueva ruralidad. En PÉREZ, E., FARAH, M. y CARTÓN DE GRAMMONT, H. La nueva ruralidad en América Latina. Avances teóricos y evidencias empíricas. Bogotá: Pontificia Universidad Javeriana y CLACSO, 2008, p. 23-44 .

ENTRENA DURÁN, F. Viejas y nuevas imágenes sociales de ruralidad. Estudos Sociedade e Agricultura, 1998, $\mathrm{n}^{\circ}$ 11, p. 76-98.

GARCÍA RAMÓN, M. D., TULLA i PUJOL, A. F. y VALDOVINOS PERDICES, N. Geografía Rural. Madrid: Síntesis, 1995.

LÓPEZ COLÁS, J. La residencia secundaria en España: estudio territorial de su uso y tenencia. Barcelona: Universitat Autónoma de Barcelona, 2003.

MANZANAL, M. Regiones, territorios e institucionalidad del desarrollo rural. Primeras Jornadas El desarrollo rural en su perspectiva institucional y territorial. Buenos Aires: IGeo/FFyL/UBA, 2005, p. 32-54.

MÉNDEZ GUTIÉRREZ DEL VALLE, R. Ciudades innovadoras y desarrollo territorial en regiones periféricas y áreas rurales. En TARROJA, A. y CAMAGNI, R. (Coords). Una nueva cultura del territorio. Barcelona: Diputació de Barcelona, 2006, p. 221-236.

MURMIS, M. y FELDMAN, S. Pluriactividad y pueblos rurales: examen de un pueblo pampeano. En NEIMAN, G. y CRAVIOTTI, C. (Comp.). Entre el Campo y la Ciudad: desafíos y estrategias de la pluriactividad en el agro. Buenos Aires: Ediciones Ciccus, 2005, p. 15-47.

NOGAR, A. G. Los espacios rurales en transformación cambios y escenarios. Tandil (Argentina): FCH-UNICEN, 2008.

PAGÈS, D. y PÉLISSIER, N. Territoires sous influence/1. Paris: L'Harmattan, 2000.

PANIAGUA MAZORRA, A y HOGGART, K. Lo rural, ¿Hechos, discursos o representaciones? Una perspectiva geográfica de un debate clásico. Globalización y Mundo Rural, 2002, nº 803, p. 61-71.

PASCIARONI, C., OLEA, M. y SCHROEDER, R. Pequeñas localidades, entre el éxodo rural y la urbanización. Evolución de las localidades rurales de la región pampeana argentina: 1960-2001. VIII Congreso Latinoamericano de Sociología Rural. Porto de Galinhas (Pernambuco, Brasil), 2010

RIELLA, A. y ROMERO, J. Nueva ruralidad y empleo no- agrícola en Uruguay. En Territorios y organización social de la agricultura. En BENDINI, M. y STEIMBREGER, N. (Coords.). Buenos Aires: GESA-Editorial La Comena, 2003. 
SÁNCHEZ JIMÉNEZ, J. La vida rural en la España del siglo XX. Barcelona: Planeta, 1975.

SANTOS, M. y SILVEIRA, M. Más allá de las metáforas. Una geografía de la globalización. Estudios Geográficos, 1998, vol. LVIX, nº 230, p. 99-112.

SANTOS, M. Horizontalidades y verticalidades. En La Naturaleza del Espacio Técnica y tiempo. Razón y emoción. Barcelona: Ariel, 1996, p.162-166.

VELTZ, P. Mondialisation, Villes et Territoire. Leconomie darchipel. PUF: Paris, 1996.

\section{RECURSOS ELECTRÓNICOS UTILIZADOS}

FERRÁS, C. El enigma de la contraurbanización: Fenómeno empírico y concepto caótico. EURE [En línea]. 2007, vol. 33, nº 98, p. 5-25.

$<$ http://www.eure.cl/numero/el-enigma-de-la-contraurbanizacion-fenomeno-empiricoy-concepto-caotico >. [26 de marzo 2012].

GÓMEZ CONTRERAS, L. M. La segunda residencia: espacios fragmentados e interconectados. Perspectiva geográfica. [En línea]. Bogotá: Universidad Pedagógica y Tecnológica de Colombia UPTC e Instituto Geográfico Agustin Codazzi IGAC, 2010, vol. 15, p. 113-124.

$<$ http://virtual.uptc.edu.co/revistas/index.php/perspectiva/article/view/1232/1185>. [15 de marzo de 2012].

INDEC. Censo Nacional de Población y Vivienda 2010. Resultados 2010. [En línea]. $<$ http://www.censo2010.indec.gov.ar/resultadosdefinitivos.asp >. [2 de abril 2012].

JACINTO, G. Asentamientos de rango menor (ARM) en Tandil: transformaciones territoriales a partir de la renovación de los vínculos urbano-rurales. Estudios Socioterritoriales. Tandil (Argentina): CIG-UNICEN, 2011, $\mathrm{n}^{\mathrm{o}}$ 10, p. 10-19. $<$ http://www.cig.org.ar/docs/NC2BA2010/Guillermina20Jacinto.pdf>. $[15$ de abril 2012].

NOGUÉ i FONT, J. El fenómeno neorural. Agricultura y Sociedad. [En línea]. Madrid: Ministerio de Agricultura, Pesca y Alimentación, 1988, nº 47, p. 145-175.

$<$ http://www.magrama.gob.es/ministerio/pags/biblioteca/revistas/pdfays/a04706.pdf $>$ [3 de mayo 2012].

PANIAGUA, A. La individualización Del mundo rural. Dimensiones analíticas para ¿Un concepto generalizable? En Revista Economía, Sociedad y territorio. [En línea]. México: El Colegio Mexiquense, A.C., 2008, vol. VIII, nº 27, p. 638-659.

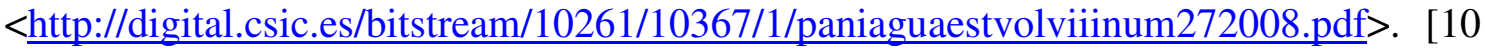
de mayo 2012]. 
SOLANA, SOLANA, M. Nuevas dinámicas en los procesos rurales: vivienda, cambio social y proceso de elitización. El caso de Empordanet (Gerona). Revista de Estudios sobre Despoblación y Desarrollo Rural. [En línea]. Zaragoza: Universidad de Zaragoza, 2006, no 5 , p. 57-87.

$<$ http://www.ceddar.org/content/files/articulof_259_03_Ager\%205,3.pdf $>. \quad[16 \mathrm{de}$ marzo 2012].

SEGRELLES SERRANO, J. A. La multifuncionalidad rural: realidad conflictiva en la unión europea, mito en América Latina. Ería Revista Cuatrimestral de Geografía. [En línea]. Departamento de Geografía, Universidad de Oviedo. (España), 2007, no 72, p. 89-99. <http://www.revistaeria.es/index.php/eria/article/view/710/687>. [23 de mayo 2012].

\section{Ge Graphos}

